\title{
Hydrophobic Aminostyryl Quinolinium Dyes as New Fluorescent Stains for Proteins in Sodium Dodecyl Sulfate-polyacrylamide Gel
}

\author{
Sooyeon Hong, Seung Soo Yoon," Chulhun Kang," and Myungkoo Suh ${ }^{*}$

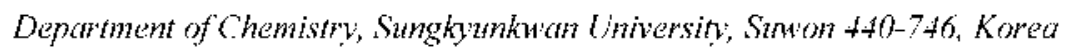 \\ "Department of Neuroscience. Graduate School of East-West Medical School. Kytang /lee University: Yongin ft9-701, Korea \\ Received November 4, 2003
}

Key Words : Aminostyryl quinolinium. Fluorescent stain, Protein staining. Stain for SDS-PAGE, Intramolecular charge transfer probe

Fluorescent stains have been increasingly used for visualizing proteins in sodium dodecyl sulfate-polyacrylamide gels (SDS-PAGE) because of their high sensitivity and ease of use. ${ }^{1,2}$ Among protein stains, dyes that bind non-covalently to protein-SDS complexes in SDS-PAGE are particularly useful for proteomic studies. ${ }^{2.3}$ Unlike covalent binders that modify proteins permanently, they maintain chemical composition of proteins. Therefore, post-gel microanalysis, such as protein characterization using mass spectrometry, is not hampered by their presence.

It is known that fluorescence of dye molecules that emit from an intramolecular charge transfer (ICl) states are extremely sensitive to medium polarity and rigidity in general. ${ }^{+.5}$ Their fluorescence intensity increases as the environment becomes less polar in aqueous solutions. Hence, fluorescent IC'I molecules are likely to be a good non-covalent stain for proteins in SDS-PAGE gel as long as they bind to protein-SDS complexes in the gel. Adding a hydrophobic tail to ICI probes is expected to facilitate their binding to protein-SDS complexes by increasing hydrophobic interaction with SDS molecules. In the past, various hydrophobic fluorescent probes have been developed mostly for biological membrane studies. For example. octadecyl rhodamine $B$ dye was used to monitor membrane fusion process. ${ }^{67}$ Fluorescein derivatives with a tail were commonly utilized for fluorescence recovery after photobleaching (FRAP) measurement of lipid lateral diffusion. ${ }^{8}$ Lipophilic coumarin derivatives were also prepared and used as a $\mathrm{pH}$ sensor. However, despite the wide application of fluorescent probes with a hydrophobic tail, only a few have been used as protein stains for SDS-l'3AGE. Merocyanine dyes with tails,

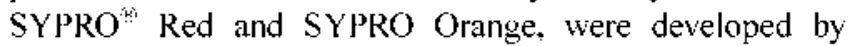
Molecular l'robes but they required 4- $10 \mathrm{ng}$ band of proteins for detection. ${ }^{10.11}$ Recently, we discovered that lipophilic fluorescein derivatives could also visualize protein bands in SDS-PAGE gels. ${ }^{\text {? }}$

In this paper, we synthesized new fluorescent dyes (Scheme 1) with aminostyryl and quinolinium moieties. which form an effective electron push-pull system resulting in fluorescence emission from an $\mid \mathrm{Cl}^{\prime}$ state $^{13}$ and an addi-

"To whom correspondenee should be addressed. Seung Soo Yoon (ssyoon@ch@mı.skku.ac.kr); Myungkoo Suh (msuh@skku.cdu)

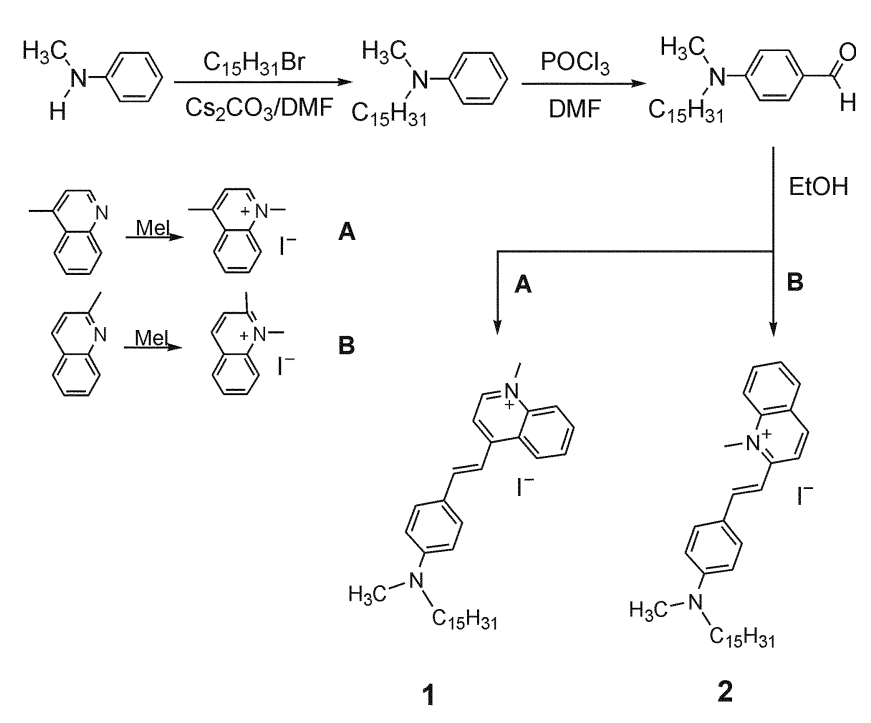

Scheme 1. Synthesis and structures of the synthesized dyes, $\mathbf{I}$ and 2.

tional hydrophobic aliphatic tail to increase the binding of the dyes to protein bands in SDS-PAGE by interacting with SDS molecules. The fluorescent dyes ( 1 and 2 ) were synthesized according to Scheme I by Knoevenagel reactions from 4-(methyl-pentadecyl-amino)-benzaldehyde and 1,4-dimethylquinoliniuın (1) or 1,2-dimethylquinolinium salts (2). Reactions were carried under refluxing condition in ethanol. Molecular structures of the fluorescent probes were confirmed by their spectroscopic data. ${ }^{14}$

In Figure 1, the effect of binding to protein-SDS complexes is demonstrated. Addition of $150 \mu \mathrm{g} / \mathrm{mL}$, bovine serum albumin (BSA) resulted in 100-fold increase of the emission intensity of 1 in $0.05 \%$ SDS. A similar intensity enhancement was observed with 2 . When bound to proteinSDS complexes, the quantum yields for the dyes increased to 0.4 . Both dyes exhibited broad fluorescence excitation bands with a maximum at $\sim 540 \mathrm{~nm}$ in the presence of proteins and SDS. Thus, they can be effectively excited with $473 \mathrm{~nm}, 488 \mathrm{~nm}$ or $532 \mathrm{~nm}$ light sources. The emission maximum for 1 was $640 \mathrm{~nm}$ while that of 2 was $600 \mathrm{~nm}$.

We applied the synthesized fluorescent dyes for staining proteins in SDS-PAGF gel. Figure 2 depicts the gel images obtained by scanning SDS-PAGE gels stained with either $\mathbf{1}$, 2, SYPRO Orange, or acidic silver staining. A broad-range 


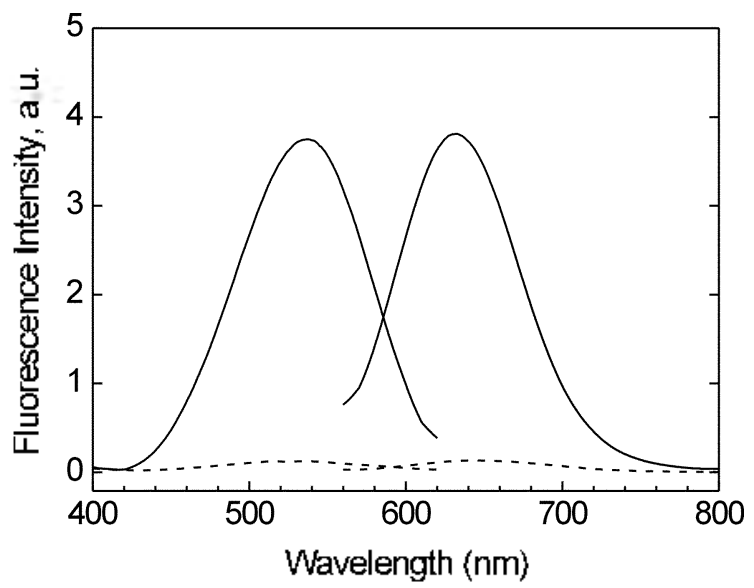

Figure 1. Hluorescence excilation and emission spectra of $\mathbf{I}$ in the presence and absence of BSA. Dashed lines represent spectra in $0.05 \%$ SDS. and solid lines are spectra with $150 \mu \mathrm{g} / \mathrm{mL}$ denatured BSA in $0.05 \%$ SDS. [1] $1 \mu \mathrm{M}$.

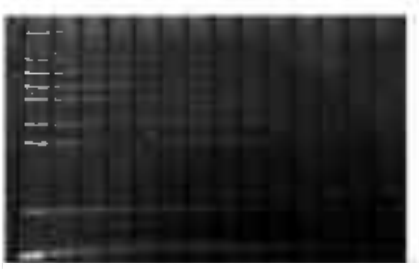

1

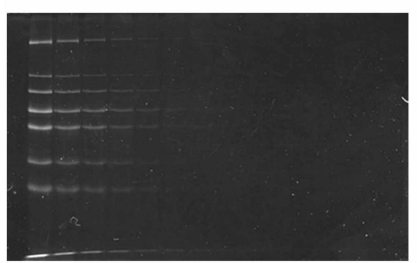

SYPRO Orange

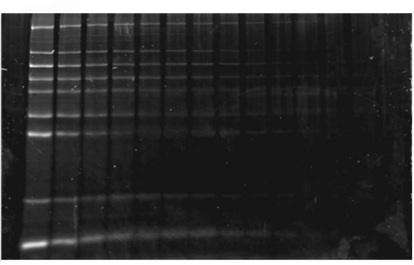

2

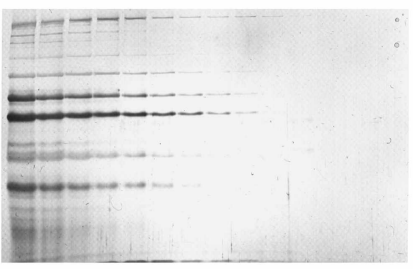

Silver
Figure 2. Comparison of SISS-PAGil: gel images visualized by various staining methods. $100 \mathrm{ng} / \mathrm{band}$ of molecular weight marker proteins were loaded at the most left lane and 2-fold diluted to the right side consecutively. Grels were stained for $1 \mathrm{~h}$ in $1 \mu \mathrm{M} 1$ or 2 dye solution conlaining 7.5\% acelic acid alter protein lixation. SYPRO Orange staining was carried out according to the previously reported protocol. ${ }^{15}$

molecular weight standard marker's containing approximately equal amount of standards were applied to each lane in two fold serial dilutions. It is clearly shown that the aminostyryl quinolinium dyes are more sensitive than SYPRO Orange. The dye, 1, detected protein band containing only 1-2 $\mathrm{ng}$ / band while SYPRO Orange required $6-12 \mathrm{ng}$ of protein. The sensitivity of 2 was higher than 1, and similar to or even superior to that of silver staining. This ortho-quinolinium derivative succeeded to visualize bands in $10^{\text {th }}$ lane, which contains only $0.2 \mathrm{ng} /$ band proteins. The observed superior sensitivity of $\mathbf{2}$ is ascribed to its higher binding affinity to protein-SDS complexes than 1 (data not shown). It is noted that the band pattern of the gel stained with 1 is similar to 2 but differs from the one stained with SYlPRO Orange. 'This difference in sensitivities depending on the nature of proteins indicates substantial contribution of the interaction between the dye and proteins, in addition to the interaction between the dye and SDS molecules.

In summary, new fluorescent aminostyryl quinolinium dyes with an aliphatic tail were synthesized and successfully applied as sensitive protein stains for SDS-J'AGE gel. This high sensitivity was attributed to their large quantum yield increase upon binding to protein-SDS complexes as well as their high binding affinity to the complexes.

Acknowledgment. 'This work was supported by a program (R05-2003-000-1 1419-0) of Korea Science and Engineering Foundation and the Brain Korea 21 Program of the Ministry of Education, Korea.

\section{References}

1. Rabilloud. T.: Chamnont. S. Proteme Reseath: Hito-Dinemsional Gel Electrophoresis and ldentification Whothods: Rabillouk. T. II., I:d.: Springer-Verlag: I Ieidelberg. 2000, Chap 5.

2. Pallon. W. I: J. Chomatogr B, 2002, 77 l. 3 and references theseir.

3. Kang. [D.: Gho. Y. S.: Sut. M.: Kang. C. Butl. Korew Chem. Soc. 2002. 23. 1511-1512.

4. Takowicz. I. R. In Principles of Fltorescerree Spectroscopy. $2^{\text {nd }}$ I:d.: Kluwer Academic:Plenum Publishers: New York. 1999: Chap. 3 and Clyap. 6.

5. Shin. E. J.: Lee. S. H. Butl. Koretn (hem. Soc 2002. 23. 1309 1314.

6. Cheetham. J. J.: Nir. S.: Johnssos. E.: Flatagass. T. D.: Epand. R. M. J. Biol. Chem. 1994. 269.5467-5472.

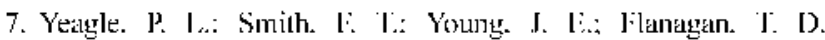
Biochemistm: 1994. 33, 1820-1827.

8. Mckay. D. A.: Kusel. I. R.: Wilkinson. P. C. J. C'tl S'j. 1991. 1010. 473-479.

9. Kraaycthof. R.: Sterk. G. J.: Sang. H. W. Biochemistry 1993. 32. $10057-10066$,

10. Steimberg. T. I I.: Jones. L. I.: I lauglend. R. P.: Singer. V. I. inal. Biochem. 1996. 239. 223-237.

1]. Steimberg. 1: H.: Haugland. R. P': Singer. V. L. Anut Brochen. 1996. $239.238-245$.

12. Kang. C.: Kim. H. I.: Kang. D.: Jung. D. Y.: Suh. M. Electrophoresis 2003. 24. 3297-3304.

13. Antonious. M. S. Spectrochim Acta Part 1 1997. 53. $317-324$.

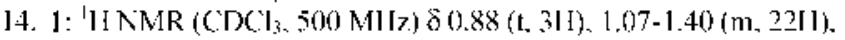
$\mathrm{I} .55-\mathrm{l} .78(\mathrm{~m} .4 \mathrm{l}) .3 .08(\mathrm{s.3} \mathrm{l}) .3 .42(\mathrm{l} .2 \mathrm{HJ}) .4 .55(\mathrm{s.} \mathrm{3H}) .6 .7 \mathrm{l}(\mathrm{d}$. $2 \mathrm{H}) .7 .56$ (d. lH). 7.67 (d. $2 \mathrm{H}) .7 .78$ (d. $1 \mathrm{H}) .7 .83-8.20$ (m. $4 \mathrm{H})$. 8.62 (d. $1 \mathrm{H}) .9 .07$ (d. ]H). HRMS $\left(\mathrm{FAB}^{+}\right) \mathrm{m} / \mathrm{L}$ calcd for $\mathrm{C}_{3.1} \mathrm{H}_{*} \mathrm{~V}_{2}^{-} .485 .3896\left(\mathrm{M}^{+}\right)$observed. 485.3884. Anal. caled for

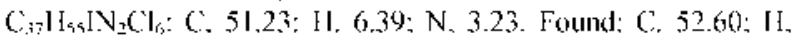
$6.37:$ N, 3.27 .

2: 'H NMR (CDCl $3.500 \mathrm{MH} / 2) \delta(0.88($ t. $3 \mathrm{H}) .1 .17-1.43$ (m. $22 \mathrm{H})$. I. $48-1.70$ (m. $4 \mathrm{H}$ ). 2.92 (s. $3 \mathrm{H}) .3 .25$ (t. $2 \mathrm{H}) .4 .56$ (s. $3 \mathrm{H}) .6 .46$ (d. $2 \mathrm{H}) .7 .48$ (d. $1 \mathrm{H}$ ). 7.61 (d. $1 \mathrm{H}) .7 .77-7.92$ (m. $4 \mathrm{H}) .8 .00$ (d. $1 \mathrm{H})$. 8.11 (d. IH). 8.45 (d. III). 8.56 (d. III). IIRMS (ГAB ${ }^{+}$) m/7. calcd

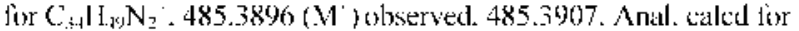

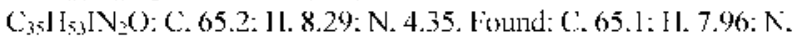
4.21 .

15. Malone. J. P.: Radabaugh. M. R.: Leimgruber. R. M.: Gerstenecker. G. S. Electrophoresis 2001. 22.919-932 